\title{
3D-SPECKLE TRACKING ECHOCARDIOGRAPHY FOR ASSESSMENT OF CORONARY ARTERY DISEASE SEVERITY IN STABLE ANGINA PECTORIS
}

\author{
By \\ Ahmed Yehia Mohamed, Sameh Refaat Allam and Ibrahim Faragallah \\ Abdelhady \\ Department of Cardiology, Faculty of Medicine, Al-Azhar University \\ *Corresponding author: Ahmed Yehia Mohamed,
}

E-Mail: dr.ahmed_yehiamohamed@gmail.com

\begin{abstract}
Background: Stable angina pectoris is a common disease that may cause disability. Echocardiography is the leading and feasible cardiac imaging in patients with cardiac disease. An early evaluation of patients with complex coronary lesions plays an important role in the prognosis and selection of treatment strategy.
\end{abstract}

Objective: To evaluate the feasibility and accuracy of 3D-speckle tracking echocardiography in assessment of coronary artery disease severity in stable angina pectoris.

Patients and methods: The study was across sectional study include 90 patients with chronic coronary syndrome(stable angina) come to Islamic cardiac center at Al-Azhar University for coronary angiography on clinical basis indications between period from April 2019 to May 2020.The patients were classified into two groups after according to the results of coronary angiography. Group (I): Case group include 60 patients with different coronary lesions in angiography, and Group (II): control group include 30 patients with normal coronary angiography. The group (I) subsequently divided into two subclasses after coronary angiography according to the Gensini score. Group (IA) non-critical stenosis ( 019 ), group (IB) critical stenosis $(\geq 20)$.

Results: There was no statistically significant difference between patients and control groups as regard demographic data and risk factors( age, gender, diabetes mellitus, hypertension, smoking, family history and dyslipidemia). There was no statistically significant difference between group (I) \&group(II) as regard their Echo parameters left atrial diameter ( LAD), left ventricular end diastolic diameter (LV EDD), left ventricular end systolic diameter (LV ESD), left ventricular end systolic volume (LV ESV ) and left ventricular ejection fraction (LV EF\%). There was statistically significant decrease in group(I) compared to group(II) as regard their 3D speckle parameters global longitudinal strain $(\mathrm{GLS} \%)(-12.35 \% \pm 2.7 \%$ versus $-20.2 \% \pm 1.19 \%)$, global circumferential strain( GCS\%)(-19.23\% $\pm 4.18 \%$ versus $-26.57 \% \pm 1.3 \%$ ), global radial strain (GRS\% )(23.48 \pm $3.32 \%$ versus $53.67 \% \pm 2.99 \%)$ and global area strain $(\mathrm{GAS} \%)(-23.98 \% \pm 4.14 \%$ versus - 
$31.93 \pm 1.28 \%$ ). Also there was significant decrease in critical stenosis group (IB) as regard 3D speckle parameters in comparison with non-critical stenosis group (IA).

Conclusion: 3D-STE is a noninvasive and handy parameter that has the potential to improve the value of echocardiography in the detection of the coronary artery disease (CAD) and to provide more information for clinical physicians. It could be expected to identify severe coronary stenosis in chronic coronary syndrome (CCS) patients even when resting wall motion and left ventricular ejection fraction were normal. It shows good sensitivity and specificity with best values for global area strain (GAS).

Keywords: 3D-Speckle Tracking Echocardiography, Coronary Artery Disease Severity, Stable Angina Pectoris

\section{INTRODUCTION}

In patients who are evaluated for chest pain (but do not have an acute coronary syndrome), non-invasive risk stratification potentially provides new opportunities for diagnosis, prognostication, treatment modifications and improved clinical outcomes (Neumannet al., 2019).

Echocardiography is the leading cardiac imaging technique in patients with suspected cardiac disease. However, conventional echocardiography at rest provides little information regarding the presence and extent of coronary artery disease (CAD) in patients suspected of suffering from stable angina pectoris (Voilliot et al., 2015).

2D STE offers the possibility of quantifying global and regional cardiac deformation noninvasively and objectively Reisner et al., (2010) But it has some limitation. It needs longer examination times and 2D imaging, prevents a full assessment of the complex three-dimensional myocardial deformation, for radial and circumferential strains in particular.

Although 2D-STE was validated for the evaluation of myocardial deformation, 3D STE has recently been regarded as a more promising technique to accurately and reproducibly evaluate the segmental and global LV function (Biswas et al., 2013).

The real-time 3-dimensional speckle-tracking echocardiography (3DSTE) can noninvasively and quantitatively assess the global and regional myocardial wall motion. The performance of this technology has been compared to the magnetic resonance imaging tagging technique (Brown et al., 2011).

Recent studies have shown that strain and strain rate in the assessment of myocardial systolic dysfunction was superior to conventional wall motion analysis and left ventricular ejection fraction (LVEF).Thus, the strain or strain rate has the potential in early evaluation of the critical coronary artery disease(Hayat et al., 2012).

The aim of the present study was to evaluate the feasibility \& accuracy of 3Dspeckle tracking echocardiography in assessment of coronary artery disease severity in stable angina pectoris.

\section{PATIENTS AND METHODS}

The study was across sectional study, include 90 patients with chronic coronary syndrome (stable angina) come to Islamic cardiac center at Al-Azhar University for coronary angiography on clinical basis indications between period from April 2019 to May 2020. 
The patients were classified into two groups after according to the results of coronary angiography. Group (I): Case group include 60 patients with different coronary lesions in angiography and Group (II): Control group include 30 patients with normal coronary angiography. The group (I) subsequently divided in two subclasses after coronary angiography according to the Gensini score. Group (IA) non-critical stenosis ( 0-19), group (IB) critical stenosis $(\geq 20)$.

Inclusion criteria: Patients between 1880 years of age and without a history of $\mathrm{CAD}$ to whom elective coronary angiography was planned. Stable angina pectoris was defined as chest pain or discomfort (angina) suspected to be due to myocardial ischemia. Symptoms of angina will be considered stable if they have been occurring over several weeks without deterioration and typically induced by activity or stress.

Exclusion criteria: Patients with poor image quality, history of myocardial infarction, history of PCI or CABG, history of cardiac pacemaker implantation, heart failure \& LVEF $<55 \%$, cardiomyopathy (of any etiology), significant valvular heart diseases (more than mild), arrhythmia, segmental LV wall-motion abnormalities, LBBB or RBBB, chronic renal failure (GFR $<60$ $\left.\mathrm{ml} / \mathrm{min} / 1.73 \mathrm{~m}^{2}\right)$, peripheral artery disease (Ankle brachial index <0.9), malignancy and use of cardio toxic medication, uncontrolled hypertension, and congenital heart disease.

All patients subjected to the following:

1-Detailed history and general \& local examinations: To obtain cardiovascular risk factors such as age, gender, smoking, hypertension, diabetes $\&$ family history of premature coronary artery disease. Also to detect the nature and type of chest pain and to exclude unstable patients. Then the clinical data, including heart rate (HR), systolic blood pressure, diastolic blood pressure, and body mass index (BMI), were measured.

2-Resting surface 12 ECG leads to detect heart rate, rhythm and chamber enlargement and ischemic changes.

3-Laboratory analyses: Complete blood count (CBC), Lipid profile including lowdensity lipoprotein (LDL-C), high-density lipoprotein cholesterol (HDL-C), cholesterol, triglycerides, and creatinine level.

4-Echocardiography: All the echocardiographic image acquisitions were performed in all the subjects before coronary angiography.

\section{Transthoracic Echocardiography:}

The examinations were carried out independently by two experienced examiners who were blinded to the study protocol and patient characteristics.

\section{Two-Dimensional Echocardiography and Measurements:}

- Aortic root (AR) ad Left atrium (LA) dimensions.

- Interventricular septal diameter (IVSD), left ventricular end diastolic diameter (LVEDD), left ventricular end sytolic diameter (LVESD) and left ventricular posterior wall diameter (LVPWD).

- LV systolic function using biplane modified Simpson's method.

- Pulsed wave Doppler Mitral inflow.

- Pulsed Tissue Doppler parameters.

Three-Dimensional Echocardiography and Measurements.

5) Angiographic assessment and Gensini score: 
All the coronary angiography (CAG) examinations were performed after the echocardiographic image acquisitions. The femoral \&radial artery approaches were used through CAG Then two independent cardiologists (interventionist) blinded to the echocardiographic results reviewed the coronary angiography of each patient to calculate the Gensini score taking into consideration 3 main parameters for each coronary lesion: severity score, region multiplying factor, and collateral adjustment factor:

1- Severity score with each step in the $25-50-75-90-99-100 \%$ diameter reduction progression. The impact on flow doubles in accordance with Poiseuille's law. Severity scores for lesions in this progression were assigned the values of $1-2-4-8-16-32$.

2- A multiplying factor was applied to each lesion score based upon its location in the coronary tree, depending on the functional significance of the area supplied by that segment. Furthermore, the Gensini score weighed according to the usual blood flow to the left ventricle in each vessel or vessel segment, with distinction between right and left dominant coronary system.

3-Collateral factor: If a segment was totally occluded or $99 \%$ stenosed and receiving collaterals, a collateral adjustment factor was used, and the adjustment was reduced by the extent of disease in the vessel that was the source of collaterals.

\section{Statistical analysis:}

Data were analyzed using Statistical Program for Social Science (SPSS) version 26.0. Quantitative data were expressed as mean \pm standard deviation (SD). Qualitative data were expressed as frequency and percentage. A one-way analysis of variance (ANOVA) when comparing between more than two means. Post Hoc test: Least Significant Difference (LSD) was used for multiple comparisons between different variables. Chi-square (X2) test of significance was used in order to compare proportions between two qualitative parameters. Pearson's correlation coefficient (r) test was used for correlating data. Binary logistic regression: was used to predict the outcome of categorical variable based on one or more predictor variables. Receiver operating characteristic (ROC curve) analysis was used to find out the over all predictivity of parameter in and to find out the best cut-off value with detection of sensitivity and specificity at this cut-off value. $P$ value $<0.05$ was considered significant.

\section{RESULTS}

There was no statistically significant difference between patients and control groups as regard demographic data and risk factors (age, gender, diabetes mellitus, hypertension, smoking, family history and dyslipidemia). There was no statistically significant difference between group (I) and group(II) as regard to their
Echo parameters regarding LAD, LV EDD, LV ESD, LV ESV and LV EF\%. There was statistically significant difference between patients group compared to control group as regard 3D speckle tracking parameters GLS\%, GCS\%, GRS\% and GAS\% (Table 1). 
DOI: $10.21608 / a m j .2021 .196424$

https://amj.journals.ekb.eg/article_196424.html

Table (1): Comparison between patients and control according to demographic data, risk factors, echo parameters and 3D speckle tracking parameters.

\begin{tabular}{|c|c|c|c|}
\hline $\begin{array}{ll}\text { Parameters } & \text { Groups } \\
\end{array}$ & Patients $(n=60)$ & Control $(n=30)$ & p-value \\
\hline \multicolumn{4}{|l|}{ Demographic data: } \\
\hline $\begin{aligned} \text { Sex : } & - \text { Female } \\
& - \text { Male }\end{aligned}$ & $\begin{array}{l}25(41.7 \%) \\
35(58.3 \%)\end{array}$ & $\begin{array}{l}9(30.0 \%) \\
21(70.0 \%)\end{array}$ & 0.282 \\
\hline $\begin{array}{c}\text { Age (years): }- \text { Mean } \pm \text { SD } \\
- \text { Range }\end{array}$ & $\begin{array}{l}58.12 \pm 5.30 \\
45-67\end{array}$ & $\begin{array}{c}56.07 \pm 6.27 \\
42-69\end{array}$ & 0.108 \\
\hline \multicolumn{4}{|l|}{ Risk factors: } \\
\hline$\overline{\mathrm{DM}}$ & $38(63.3 \%)$ & $14(46.7 \%)$ & 0.131 \\
\hline HTN & $41(68.3 \%)$ & $15(50.0 \%)$ & 0.091 \\
\hline Smoking & $24(40.0 \%)$ & $12(40.0 \%)$ & 1.000 \\
\hline $\mathrm{FH}$ & $9(15.0 \%)$ & $7(23.3 \%)$ & 0.330 \\
\hline Dyslipidemia & $23(38.3 \%)$ & $6(20.0 \%)$ & 0.079 \\
\hline \multicolumn{4}{|l|}{ Echo parameters: } \\
\hline $\begin{array}{l}\text { LAD }(\mathbf{m m}) \\
\text { Mean } \pm \text { SD } \\
\text { Range }\end{array}$ & $\begin{array}{l}33.45 \pm 8.33 \\
3.1-56\end{array}$ & $\begin{array}{l}35.87 \pm 5.42 \\
27-56\end{array}$ & 0.413 \\
\hline $\begin{array}{l}\text { LV EDD }(\mathbf{m m}) \\
\text { Mean } \pm \text { SD } \\
\text { Range }\end{array}$ & $\begin{array}{l}46.32 \pm 10.22 \\
\quad 4.5-57 \\
\end{array}$ & $\begin{array}{c}49.00 \pm 4.2 \\
40-57\end{array}$ & 0.172 \\
\hline $\begin{array}{l}\text { LV ESD (mm) } \\
\text { Mean } \pm \text { SD } \\
\text { Range }\end{array}$ & $\begin{array}{l}29.41 \pm 7.07 \\
3-39\end{array}$ & $\begin{array}{l}30.97 \pm 4.25 \\
23-39\end{array}$ & 0.935 \\
\hline $\begin{array}{l}\text { LV EDV (ml) } \\
\text { Mean } \pm \text { SD } \\
\text { Range }\end{array}$ & $\begin{array}{c}115.97 \pm 23.14 \\
70-158\end{array}$ & $\begin{array}{c}119.17 \pm 26.95 \\
59-158\end{array}$ & 0.560 \\
\hline $\begin{array}{l}\text { LV ESV (ml) } \\
\text { Mean } \pm \text { SD } \\
\text { Range }\end{array}$ & $\begin{array}{c}42.46 \pm 13.26 \\
18.5-63\end{array}$ & $\begin{array}{c}44.23 \pm 14.22 \\
18-63\end{array}$ & 0.561 \\
\hline $\begin{array}{l}\text { LV EF\% } \\
\text { Mean } \pm \text { SD } \\
\text { Range }\end{array}$ & $\begin{array}{l}64.71 \pm 6.88 \\
55.2-82.1\end{array}$ & $\begin{array}{c}63.8 \pm 7.49 \\
55-82\end{array}$ & 0.566 \\
\hline \multicolumn{4}{|l|}{ 3D speckle: } \\
\hline $\begin{array}{l}\text { GLS\% } \\
\text { Mean } \pm \text { SD } \\
\text { Range }\end{array}$ & $\begin{array}{l}-12.35 \pm 2.70 \\
-17--6 \\
\end{array}$ & $\begin{array}{l}-20.20 \pm 1.19 \\
-22--18\end{array}$ & $<0.001$ \\
\hline $\begin{array}{l}\text { GCS\% } \\
\text { Mean } \pm \text { SD } \\
\text { Range }\end{array}$ & $\begin{array}{l}-19.23 \pm 4.18 \\
-26--12\end{array}$ & $\begin{array}{l}-26.57 \pm 1.30 \\
-30--25\end{array}$ & $<0.001$ \\
\hline $\begin{array}{l}\text { GRS\% } \\
\text { Mean } \pm \text { SD } \\
\text { Range }\end{array}$ & $\begin{array}{c}23.48 \pm 3.32 \\
18-29\end{array}$ & $\begin{array}{l}53.67 \pm 2.99 \\
49-58\end{array}$ & $<0.001$ \\
\hline $\begin{array}{l}\text { GAS\% } \\
\text { Mean } \pm \text { SD } \\
\text { Range }\end{array}$ & $\begin{array}{l}-22.02 \pm 4.17 \\
-27--13 \\
\end{array}$ & $\begin{array}{l}-31.93 \pm 1.28 \\
-35--30 \\
\end{array}$ & $<0.001$ \\
\hline
\end{tabular}


DOI: $10.21608 / a m j .2021 .196424$

https://amj.journals.ekb.eg/article_196424.html

In patient group there was $37(61.7 \%)$

patients with non-critical coronary

coronary stenosis according to GENSINI stenosis and $23(38.3 \%)$ with critical score (Table 2).

Table (2): GENSINI score distribution of the patients group.

\begin{tabular}{|l|c|}
\hline GENSINI score & Patients $(\mathbf{n = 6 0})$ \\
\hline Mean \pm SD & $20.02 \pm 15.86$ \\
\hline Range & $2-83$ \\
\hline Noncritical stenosis & $37(61.7 \%)$ \\
\hline Critical stenosis & $23(38.3 \%)$ \\
\hline
\end{tabular}

There was no statistically significant difference between non-critical stenosis and critical stenosis sub-groups according to demographic data. There was statistically significant increase in smoking in critical stenosis sub-group compared to non-critical stenosis, other risk factors showed that there was no significant difference between two sub-groups. There was no statistically significant difference between non-critical stenosis sub-group and critical stenosis sub-group according to echo parameters. There was statistically significant difference between non-critical stenosis and critical stenosis sub-groups according to their 3D speckle tracking parameters GLS5, GCS\%, GRS\% and GAS\% (Table 3). 
Table (3): Comparison between non-critical stenosis and critical stenosis sub-groups according to demographic data, risk factors, echo parameters, 3D Speckle tracking parameters.

\begin{tabular}{|c|c|c|c|}
\hline Demographic data & $\begin{array}{c}\text { Noncritical } \\
\text { stenosis }(n=37)\end{array}$ & $\begin{array}{c}\text { Critical stenosis } \\
(\mathrm{n}=23)\end{array}$ & p-value \\
\hline $\begin{array}{l}\text { Sex } \\
\text { Female } \\
\text { Male }\end{array}$ & $\begin{array}{l}16(43.2 \%) \\
21(56.8 \%)\end{array}$ & $\begin{array}{c}9(39.1 \%) \\
14(60.9 \%)\end{array}$ & 0.753 \\
\hline $\begin{array}{l}\text { Age (years) } \\
\text { Mean } \pm \text { SD } \\
\text { Range } \\
\end{array}$ & $\begin{array}{c}58.46 \pm 5.23 \\
45-67\end{array}$ & $\begin{array}{c}57.57 \pm 5.49 \\
50-67\end{array}$ & 0.530 \\
\hline \multicolumn{4}{|l|}{ Risk factors: } \\
\hline $\begin{array}{l}\text { DM } \\
\text { HTN } \\
\text { Smoking } \\
\text { FH } \\
\text { Dyslipidemia }\end{array}$ & $\begin{array}{c}21(56.8 \%) \\
27(73.0 \%) \\
11(29.7 \%) \\
6(16.2 \%) \\
15(40.5 \%)\end{array}$ & $\begin{array}{l}17(73.9 \%) \\
14(60.9 \%) \\
13(56.5 \%) \\
3(13.0 \%) \\
8(34.8 \%)\end{array}$ & $\begin{array}{c}0.18 \\
0.327 \\
0.039 \\
0.738 \\
0.656\end{array}$ \\
\hline \multicolumn{4}{|l|}{ Echo parameters: } \\
\hline $\begin{array}{l}\text { LAD }(\mathbf{m m}) \\
\text { Mean } \pm \text { SD } \\
\text { Range }\end{array}$ & $\begin{array}{c}33.05 \pm 8.27 \\
3.1-44\end{array}$ & $\begin{array}{c}34.10 \pm 8.56 \\
3.3-56\end{array}$ & 0.638 \\
\hline $\begin{array}{l}\text { LV EDD }(\mathbf{m m}) \\
\text { Mean } \pm \text { SD } \\
\text { Range }\end{array}$ & $\begin{array}{c}46.10 \pm 10.62 \\
5-57\end{array}$ & $\begin{array}{c}46.68 \pm 9.78 \\
4.5-53\end{array}$ & 0.833 \\
\hline $\begin{array}{l}\text { LV ESD }(\mathbf{m m}) \\
\text { Mean } \pm \text { SD } \\
\text { Range }\end{array}$ & $\begin{array}{c}29.08 \pm 7.15 \\
3.4-39\end{array}$ & $\begin{array}{c}29.94 \pm 7.06 \\
3-36\end{array}$ & 0.651 \\
\hline $\begin{array}{l}\text { LV EDV (ml) } \\
\text { Mean } \pm \text { SD } \\
\text { Range }\end{array}$ & $\begin{array}{c}116.91 \pm 20.96 \\
88.1-158\end{array}$ & $\begin{array}{c}114.45 \pm 26.70 \\
70-158\end{array}$ & 0.693 \\
\hline $\begin{array}{l}\text { LV ESV (ml) } \\
\text { Mean } \pm \text { SD } \\
\text { Range }\end{array}$ & $\begin{array}{c}41.58 \pm 12.54 \\
21.2-61\end{array}$ & $\begin{array}{c}43.88 \pm 14.51 \\
18.5-63\end{array}$ & 0.517 \\
\hline $\begin{array}{l}\text { LV EF \% } \\
\text { Mean } \pm \text { SD } \\
\text { Range }\end{array}$ & $\begin{array}{l}64.88 \pm 7.27 \\
55.2-82.1\end{array}$ & $\begin{array}{c}64.45 \pm 6.34 \\
58-77\end{array}$ & 0.817 \\
\hline \multicolumn{4}{|l|}{ 3D Speckle: } \\
\hline $\begin{array}{l}\text { GLS\% } \\
\text { Mean } \pm \text { SD } \\
\text { Range }\end{array}$ & $\begin{array}{c}-14.03 \pm 1.36 \\
-17--11 \\
\end{array}$ & $\begin{array}{c}-9.65 \pm 2.04 \\
-13--6 \\
\end{array}$ & $<0.001$ \\
\hline $\begin{array}{l}\text { GCS\% } \\
\text { Mean } \pm \text { SD } \\
\text { Range }\end{array}$ & $\begin{array}{c}-21.78 \pm 3.08 \\
-26--16\end{array}$ & $\begin{array}{c}-15.13 \pm 1.63 \\
-18--12\end{array}$ & $<0.001$ \\
\hline $\begin{array}{l}\text { GRS\% } \\
\text { Mean } \pm \text { SD } \\
\text { Range }\end{array}$ & $\begin{array}{c}21.92 \pm 2.87 \\
18-28\end{array}$ & $\begin{array}{c}26.00 \pm 2.30 \\
21-29\end{array}$ & $<0.001$ \\
\hline $\begin{array}{l}\text { GAS\% } \\
\text { Mean } \pm \text { SD } \\
\text { Range }\end{array}$ & $\begin{array}{c}-24.81 \pm 1.29 \\
-27--22\end{array}$ & $\begin{array}{c}-17.52 \pm 3.12 \\
-24--13\end{array}$ & $<0.001$ \\
\hline
\end{tabular}


DOI: 10.21608/amj.2021.196424

https://amj.journals.ekb.eg/article_196424.html

There was significant Positive correlation between GENSINI score and 3D Speckle tracking parameters GLS\%, GCS\%, and GAS\%, while there was significant Positive correlation between GENSINI score and GRS\%. ( $\mathrm{r}=-0.806, \mathrm{P}<0.001$ for GAS score, GLS; $\mathrm{r}=-0.832, \mathrm{P}<0.001$, GCS: $r=-0.705, p<0.001$, GRS: $r=-0.427$, p 0.042 (Table 4).

Table (4): Correlation between GENSINI score with all parameters, using Pearson Correlation coefficient in patients group.

\begin{tabular}{|l|c|c|}
\hline \multirow{2}{*}{ Parameters } & \multicolumn{2}{|c|}{ GENSINI score } \\
\cline { 2 - 3 } & $\mathbf{r}$ & p-value \\
\hline Age (years) & -0.087 & 0.511 \\
\hline LAD $(\mathrm{mm})$ & -0.094 & 0.477 \\
\hline LV EDD $(\mathrm{mm})$ & -0.003 & 0.982 \\
\hline LV ESD $(\mathrm{mm})$ & -0.048 & 0.715 \\
\hline LV EDV (ml) & -0.066 & 0.619 \\
\hline LV ESV $(\mathrm{ml})$ & -0.184 & 0.159 \\
\hline LV EF\% & -0.160 & 0.221 \\
\hline GLS\% & -0.832 & $<0.001$ \\
\hline GCS\% & -0.705 & $<0.001$ \\
\hline GRS\% & -0.427 & 0.042 \\
\hline GAS\% & -0.847 & $<0.001$ \\
\hline
\end{tabular}

r-Pearson Correlation coefficient.

P-value $>0.05$ NS, *p-value $<0.05 \mathrm{~S}, * *$ p-value $<0.001 \mathrm{HS}$

All 3D speckle indices were significant predictors of severe coronary artery disease in included patients as denoted by the significantly large area under the curves (AUCs). Receiver operator characteristic analyses were performed to find out ideal strain cutoff values to detect severe coronary artery disease defined as Gensini score $\geq 20$. A GLS value of $>-12$ has
$82.6 \%$ sensitivity and $94.6 \%$ specificity; A GAS value of $>-23$ has $95.7 \%$ sensitivity and $86.5 \%$ specificity to detect critical CAD. These results suggest that resting 3D-STE is a good clinical tool for detecting severe stenosis in patients with normal EF. GAS had the best diagnostic value (Table 5) (figure1).

Table (5): Receiver-operating characteristic (ROC) curve for prediction of severe coronary artery disease using the 3D SPECKLE.

\begin{tabular}{|l|c|c|c|c|c|c|}
\hline 3D SPECKLE & Cut-off & Sen. & Spe. & PPV & NPV & Accuracy \\
\hline GAS\% & -23 & $95.7 \%$ & $86.5 \%$ & $81.5 \%$ & $97 \%$ & $97.9 \%$ \\
\hline GCS\% & -18 & $91.3 \%$ & $81.1 \%$ & $75.0 \%$ & $93.7 \%$ & $92.1 \%$ \\
\hline GLS\% & -12 & $82.6 \%$ & $94.6 \%$ & $90.5 \%$ & $89.7 \%$ & $89.6 \%$ \\
\hline GRS\% & $>24$ & $87.0 \%$ & $83.8 \%$ & $76.9 \%$ & 91.25 & $84.4 \%$ \\
\hline
\end{tabular}



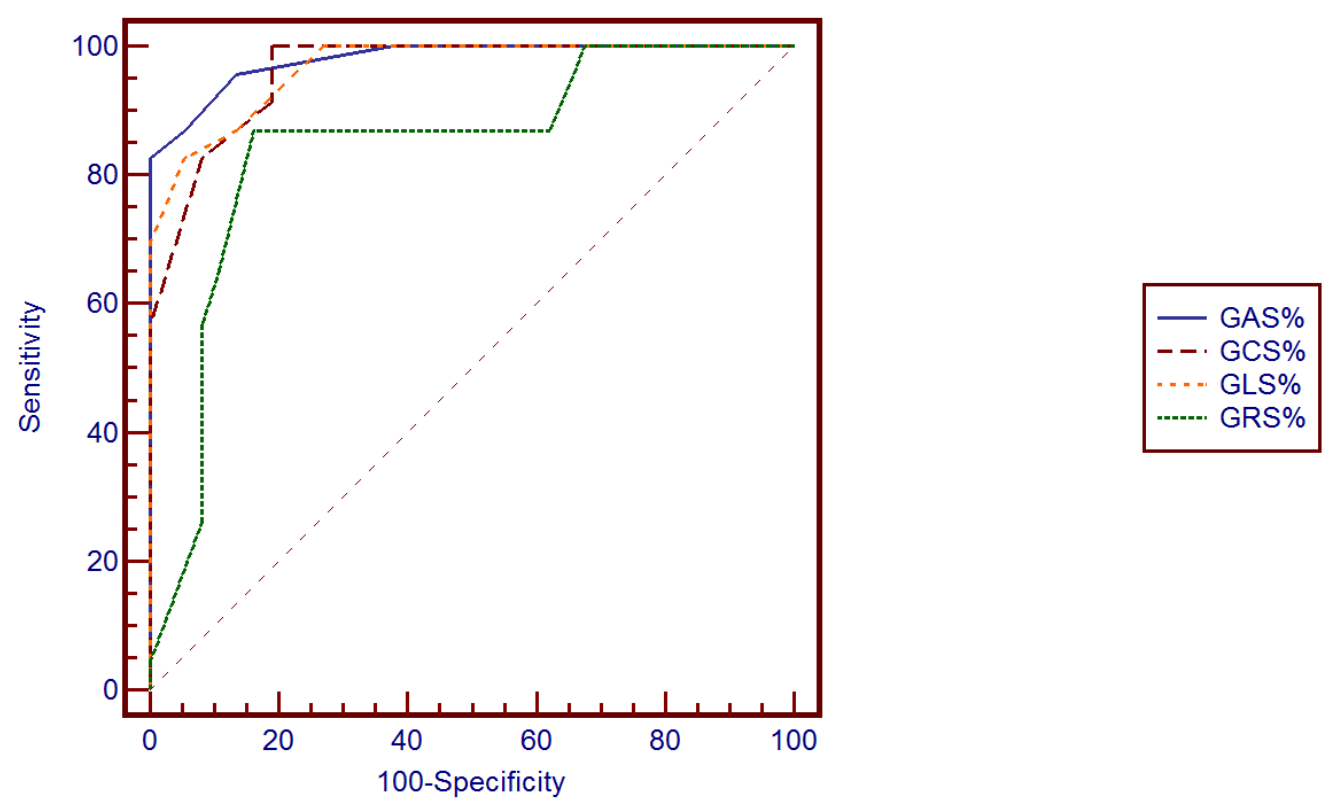

Figure (1): Receiver-operating characteristic (ROC) curve for prediction of severe coronary artery disease using the 3D Speckle tracking parameters.

\section{DISCUSSION}

Three- dimensional speckle tracking parameters were measured in our study and results reveals that worsening of all measured stain parameter with increasing severity of CAD i.e. increase Gensini score.

All strain parameters had significantly high sensitivity for the detection of the critical CAD.

This study found GAS to be superior to other strain parameters like CS, RS, LS. and it has the highest diagnostic value for detection of CAD severity in stable CAD with sensitivity and specificity of $95.7 \%$ and $91.5 \%$, respectively.

The detection of coronary artery severity is important for prognosis \& risk stratification which implicate on decision of treatment later on.

Gensini score could be used to predict the cardiovascular prognosis during a long- term follow-up of CAD patients ( Zhang et al., 2013).

These results coincide with results of Dogdus et al. (2019) which showed that GAS has the highest sensitivity and specificity to detect critical CAD. They study patients without a history of CAD \& without RWMA to whom elective coronary angiography was planned after positive stress test or myocardial perfusion scintigraphy. They used the same parameters for 3D-STE, global longitudinal strain (GLS), global circumferential strain (GCS), global radial strain (GRS), and global area strain (GAS) were measured before coronary angiography They used Gensini score to categories the severity of CAD. A Gensini score of $\geq 20$ was accepted as critical CAD. Correlation between Gensini scores and 3D-STE results were evaluated.

The results showed that Mean GLS was 12, GCS was -18.8 , GRS was 33.4 , GAS was -28.9, and mean Gensini score was 18.8. GLS and all other strain parameters 
were significantly worse in patients with critical CAD group compared with noncritical CAD group and also positive linear correlation was observed between Gensini score and all measured strain parameters $(r=0.568, P<0.001$ for Gensini score and GLS; $r=0.617, P<$ 0.001 for Gensini score and GAS). A GLS value of $>-10$ has $88.9 \%$ sensitivity and $92.9 \%$ specificity; A GAS value of $>-21$ has $97.2 \%$ sensitivity and $88.1 \%$ specificity to detect critical CAD. And concluded that 3D-STE is a noninvasive and handy parameter to detect subclinical left ventricular dysfunction and global strain values were significantly correlated with CAD severity. GAS has the sensitivity of $97.2 \%$ and specificity of $88.1 \%$ to detect critical CAD. Adding 3D strain echocardiography to exercise test or myocardial perfusion scintigraphy might increase sensitivity to detect critical CAD in clinical practice (Dogdus et al., 2019).

The same idea detection of severity of coronary artery disease in stable angina by 3D STE in El-Benny et al. (2020).

But it is different in the anatomical score used for CAG (SYNTAX score) and included patients with or without RWMA. The parameters used for 3D-STE are global longitudinal strain (GLS), global circumferential strain (GCS), global radial strain (GRS), and global area strain (GAS). Patients were sub grouped into low, intermediate \& high SYNTAX scores, then correlation between 3D STE \& SYNTAX score was done.

There was a significant difference in strain measurement (Global longitudinal, circumferential and radial strain) between SYNTAX score sub-groups. The absolute value of different strain measurements decreased from low SYNTAX score to intermediate or high SYNTAX scores. For GLS was $-14.8 \pm 1.9 \%,-11.08 \pm 1.7$ and -7.4 \pm 1.2 , respectively, and for GAS was -
$39.5 \pm 1.08,-25.95 \pm 7.09$ and $-14.6 \pm 1.86$, respectively, and for GCS was $24.47 \pm 3.89,-14.96 \pm 2.41$ and $-8.73 \pm 2.53$, respectively, using ROC curve analysis the cut off value of GLS that differentiate between high SYNTAX score $(\geq 33)$ and non-high score $(\leq 32)$ was -7.7 with a sensitivity of $87.5 \%$ and a specificity of $98.1 \%$ and -17.1 for GAS with a sensitivity of $100 \%$ and specificity of $88.5 \%$ and -12.5 for GCS with a sensitivity of $100 \%$ and specificity of $92.3 \%$. The cut off value of GLS that differentiate between low SYNTAX score $(\leq 22)$ and non-low score $(\geq 23)$ was-12.5.

El-benny et al. (2020) in agreement with our study Three-dimensional -STE is a noninvasive, reproducible, and efficient tool that has a potential clinical practice to evaluate the coronary lesion in chronic coronary syndrome patients, but the discrepancy in cutoff values because the different anatomical score used ( SYNTAX score).

Sun et al. (2015) used 3D echo in detection of coronary artery disease. They did not measured only the peak values of longitudinal strain (LS), circumferential strain (CS), radial strain (RS) and area strain (AS), but also the time to peak value of these strains (T-LS, T-CS, T-RS and T-AS) and the combinations of the peak strain value and time to peak of these strain RS1, CS1, LS1 and AS1 (composite indices) were measured.

The results showed that each individual peak value of strain had no diagnostic value for the early detection of CAD. Only T-LS had statistical significance in the diagnosis of CAD. However, the composite index of peak strain and time to peak strain had significantly higher sensitivity for the detection of CAD. Which means that resting 3D-STE had value for the early detection of CAD, and the sensitive indicators were T-LS, CS1, 
LS1 and AS1. LS1 has the highest sensitivity of $61.8 \%$

Lin et al. (2017) coincides with our study that 3D global strain values were significantly correlated with CAD severity in patients without RWMA. It shows that GAS and 3D- strain (which represents the expansion and contractions of a pair of points sets in the same radial line) had a better diagnostic value for severe stenosis with GAS cutoff value -29 with sensitivity \& specificity was $95 \%$ \& $71 \%$ respectively. But it differs in angiographically scoring system of coronary arteries. It used the most severe single coronary artery stenosis.

Global peak systolic longitudinal strain (GPSLS), global circumferential strain (GCS), global area strain (GAS), and global radial strain (GRS assessed by 3DSTE at rest was studied in patients with NSTE-ACS by Biswas et al. (2018) and concluded that GPSLS was significantly lower in patients with significant stenosis and might be useful for identifying patients with a significant stenosis with good degree of sensitivity and specificity.

Receiver operator characteristic curve for GPSLS, circumferential strain (CS), area strain (AS) and radial strain (RS) as predictor of significant CAD on angiogram had shown AUC for GPSLS $0.840 \mathrm{P}=0.001$; as compared to AUC for circumferential strain $0.689 \mathrm{P}=0.014$; area strain $0.774, \mathrm{P} \leq 0.001$ and radial strain $0.222, \mathrm{P} \leq 0.001$ with an optimal cutoff value of $-13.50 \%$ (sensitivity \& specificity of $88.9 \%$ and $70.8 \%$ respectively significant coronary artery stenosis defined as stenosis $70 \%$ or more for three epicardial vessels and $50 \%$ or more for LM coronary artery was considered as significant coronary stenosis.

Another study for NSTE-ACS patients Cai et al. (2016) that show results concedes with Biswas et al. (2018) regarding the high sensitivity and specificity of cutoff value of GPLS. It differs from Biswas et al. (2013) that only GPLS is assessed by 3D-STE (other strain values not assessed) \& the anatomical score used is SYNTAX score (i.e more detailed scoring system). The absolute value of GPLS is significantly associated with the complexity of coronary artery lesions in the NSTE-ACS patients. The values of GPLS significantly decreased from low SYNTAX scores to intermediate or high SYNTAX scores ($14.0 \pm 2.7 \%$ and $-9.5 \pm 2.8 \%$, respectively, $\mathrm{P}<0.001)$. The area under the receiver operator characteristic curve (AUC) for GPLS to evaluate patients with complex NSTE-ACS was 0.882 (95\% confidence interval [CI], 0.797-0.967, $\mathrm{P}<0.001)$ with an optimal cutoff value of $-11.76 \%$ (sensitivity $82.6 \%$ and specificity $83.3 \%$ ) (Cai et al., 2016).

There were a limited number of studies on the use of 3D-STE to assess the extent of coronary artery. However, there were several previous studies which used 2DSTE to evaluate the myocardial deformation were in agreement with our findings.

Choi et al. (2013) measured global longitudinal strain by $2 \mathrm{~d}$ speckle tracking for predicts the presence of left main and three vessel coronary artery disease in patients without regional wall motion abnormality. There were a discrepancy in the value of GLPS in Choi et al. (2013) results which showed that $-17.9 \%$ appears to be a helpful cutoff value for discriminating those with severe CAD (specificity $79 \%$ and sensitivity $79 \%$ ). They assessed the number of affected vessels, using a cutoff of percent diameter stenosis $70 \%$ for three epicardial vessels and $50 \%$ for LM coronary artery in our study, we used a more detailed anatomical 
score and we use $3 \mathrm{~d}$ speckle not $2 \mathrm{D}$ and we get more sensitivity \&specificity.

\section{Conclusion:}

3D-STE is a noninvasive and handy parameter that has the potential to improve the value of echocardiography in the detection of the coronary artery disease (CAD) and to provide more information for clinical physicians. It could be expected to identify severe coronary stenosis in chronic coronary syndrome (CCS) patients even when resting wall motion and left ventricular ejection fraction were normal. It shows good sensitivity and specificity with best values for global area strain (GAS).

\section{REFERENCES}

\section{BiswasAK, Haque T, Banik}

D, Choudhury SR, Khan SR, FazilaTun NM. (2018): Identification of significant coronary artery disease in patients with non-ST segment elevation acute coronary syndrome by myocardial strain analyses using three dimensional speckle tracking echocardiography. Echocardiography, 35(12):1988-1996.

Biswas M, Sudhakar S and Nanda NC. (2013): Two- and three-dimensional speckle tracking echocardiography: clinical applications and future directions. Echocardiography, 30:88-105.

Brown J, Jenkins C, Marwick TH. (2011): Use of myocardial strain to assess global left ventricular function: a comparison with cardiac magnetic resonance and 3-dimensional echocardiography. Am Heart J., 157: 1015.

Cai Z, Dai J, Wu D, Qiu J, Ma J, Li G and Xu L. (2016): The value of 3dimensional longitudinal strain in the evaluation of complex coronary lesions in non-ST-segment elevation acute coronary syndrome patient. Medicine (United States), 95(39): 1-7.

Choi JO, Cho SW and Song YB. (2013): Longitudinal 2D strain at rest predicts the presence of left main and three vessel coronary artery disease inpatients without regional wall motion abnormality. Eur $\mathbf{J}$ Echocardiogr., 10:695-701.

Dogdus M, Simsek E, Cinar CS. (2019): Speckle tracking echocardiography for assessment of coronary artery disease severity in stable angina pectoris. Echocardiography, 36(2):320-327.

El-benny AM, Elsayed $Y$ and Al-Amin AM. (2020): The value of 3-dimensional speckle tracking echocardiography in the diagnosis and evaluation of coronary lesions in stable angina pectoris patients. Al-Azhar Med J., 49(3): 1429-1440.

Hayat D, Kloeckner $M$ and Nahum J. (2012): Comparison of real-time threedimensional speckle tracking to magnetic resonance imaging in patients with coronary heart disease. Am J Cardiol., 109:180-6.

Lin L, Ping-Yang Z, Hong R, Jing D, Ling-Ling $F$ and Qian-Shan $D$. (2017): Evaluation of left ventricular myocardial mechanics by threedimensional speckle tracking echocardiography in the patients with different graded coronary artery stenosis. The International Journal of Cardiovascular Imaging, 33: 1513-1520.

Neumann FJ, Sousa-Uva M, Ahlsson A, Alfonso F, Banning AP, Benedetto U and Roffi M. (2019): 2018 ESC/EACTS Guidelines on myocardial revascularization. European Heart Journal, 40(2), 87-165.

$\begin{array}{lll}\text { Reisner } & \text { SA, Lysyansky } & \text { P, Agmon } \\ \text { Y, Mutlak D, Lessick J and } & \text { Friedman }\end{array}$ 
Z. (2010): Global longitudinal strain: a novel index of left ventricular systolic function. J Am SocEchocardiogr., 17(6):630-3.

Sun YJ, Wang F, Zhang R, Wang H, Yang C, Cai J, Zang W, Li M, Qi X and Li J. (2015): Incremental value of resting three-dimensional speckle-tracking echocardiography in detecting coronary artery disease. ExpTher Med., 9(6): 20432046.

Voilliot D, Huttin O, Hammache N, Cicoira M, Rossi A. (2015): Impact of Global and Segmental Hypertrophy on
Two-Dimensional Strain Derived from Three-Dimensional Echocardiography in Hypertrophic Cardiomyopathy: Comparison with Healthy Subjects. J Am SocEchocardiogr., 28:1093-102.

Zhang L, Gao J, Xie M, Balluz $R$ and Shuping G (2013): Left ventricular threedimensional global systolic strain by realtime three-dimensional speckle-tracking in children: feasibility, reproducibility, maturational changes, and normal ranges. J Am SocEchocardiogr., 26:853-9. 
تقييم شدة قصور الثر ايين التاجية بو اسطة التنبع النقطي ثثلاثي الأبعاد للبطين الأيسر في مرضى قصور الثريان التاجي المستقر

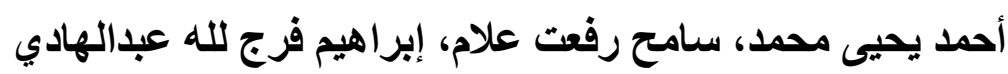

قسم القلب والأوعية الاموية , كلية الطب - جامعة الأزهر

E-Mail: dr.ahmed_yehiamohamed@gmail.com

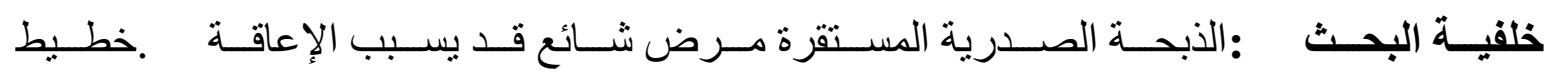

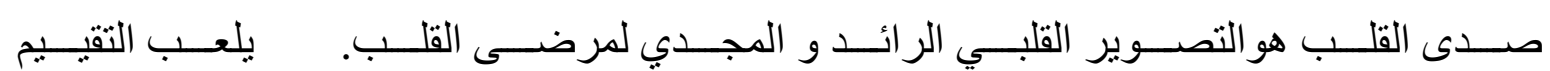

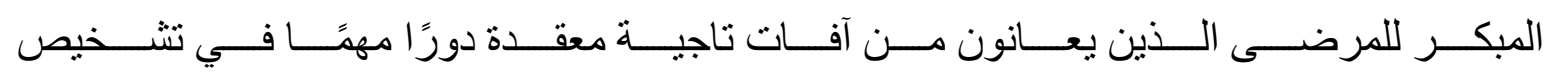
واختيار استر اتيجية العلاج.

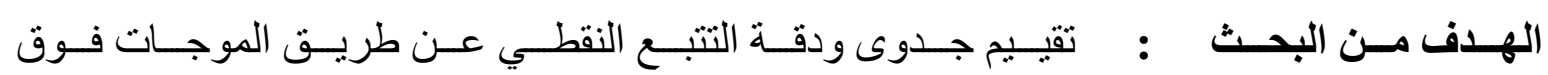

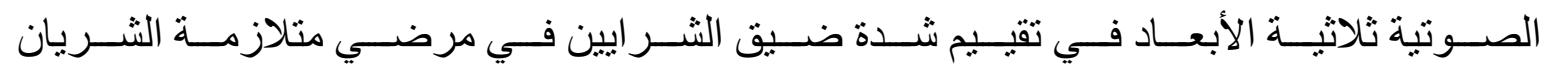

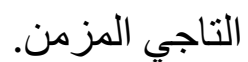

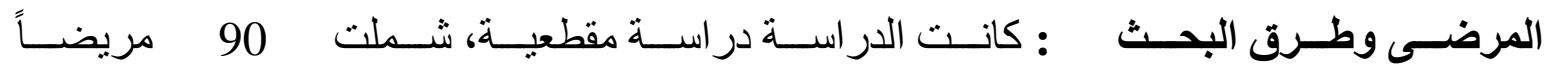

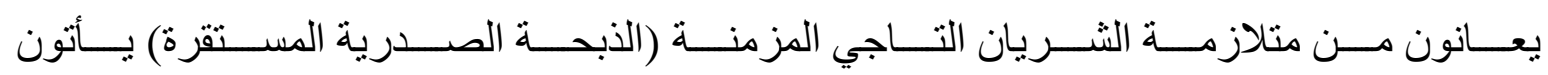

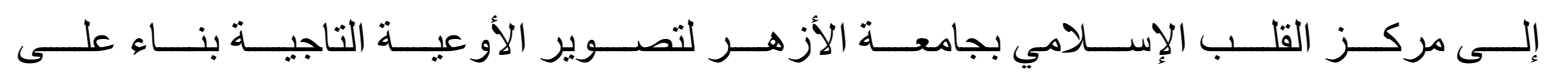

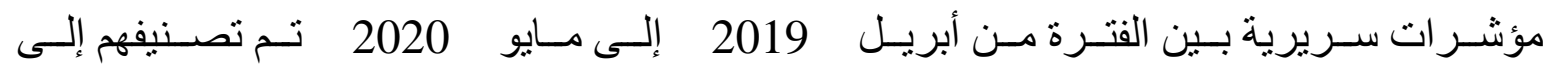

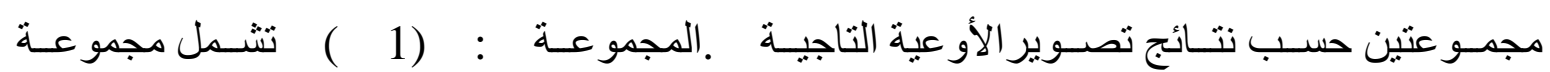

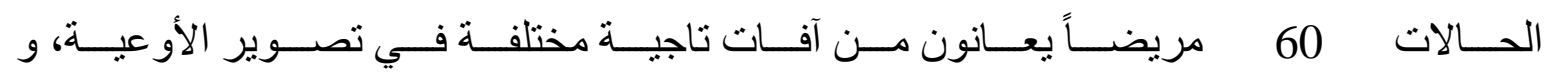

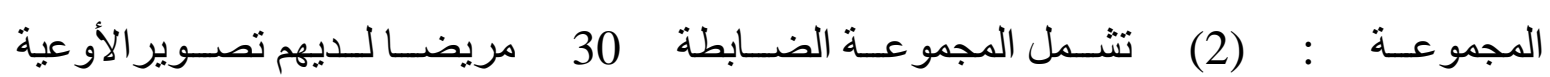

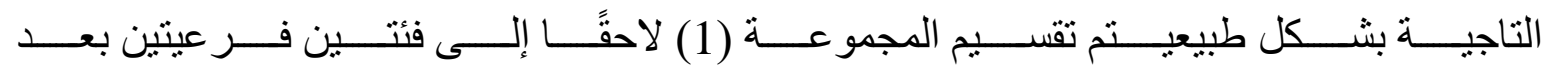

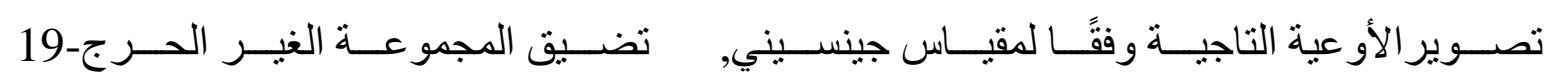

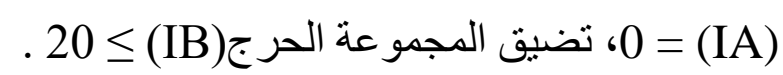

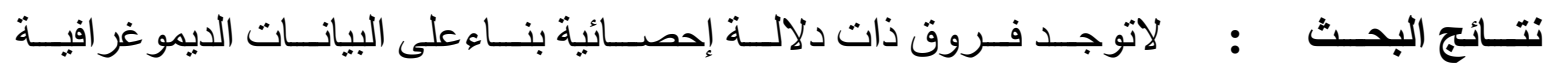

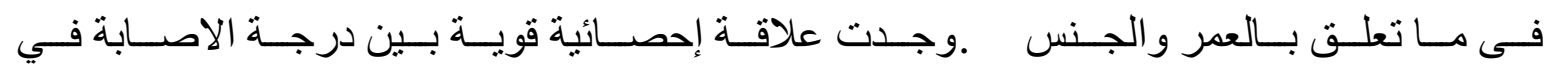

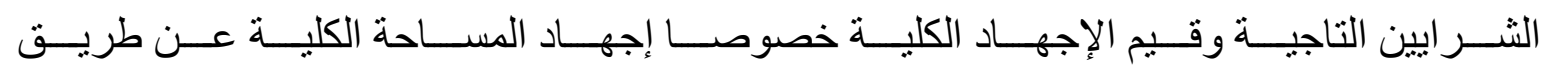

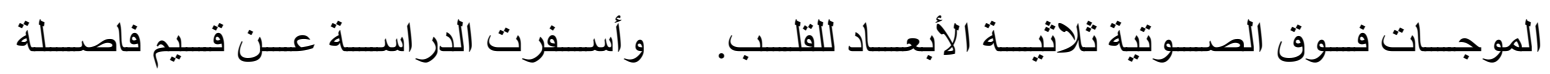

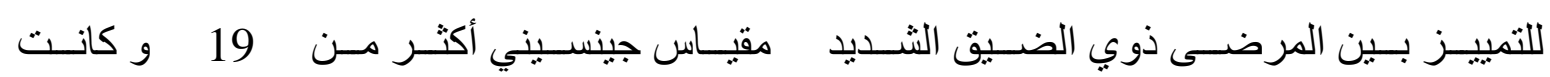




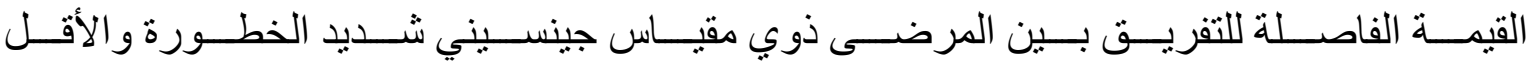

$$
\text { خطورة هي } 26 \text { - لإجهاد المساحة الكلي و } 12 \text { ـ للإجهاد الطولي الكلي. }
$$

الاسـتنتاج : تخطـيط صــدى القلـب عـن طريـق التتبـع النقطـي ثلاتـي الأبعـاد هـي وسـيلة

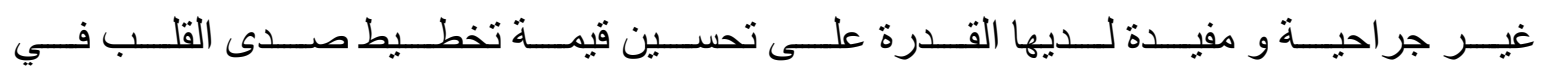

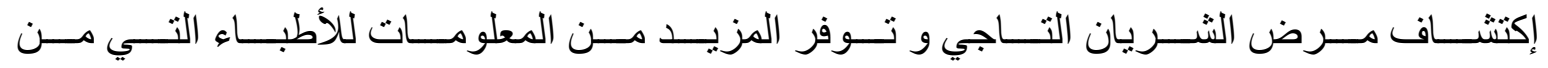

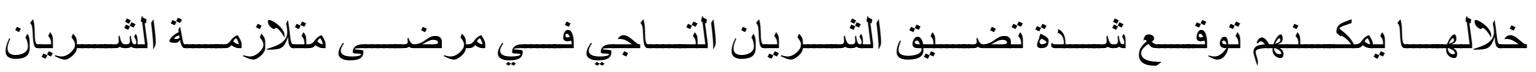

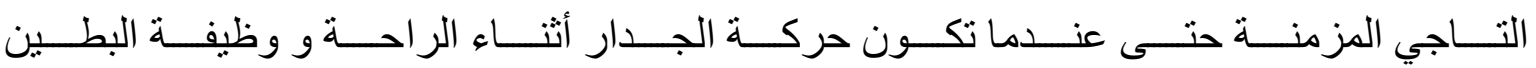
الايسر الانقباضية طبيعية.

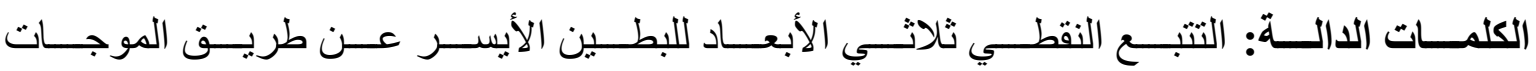
الصوتية, شدة ضيق الثر ايين التاجية, الذبحة الصدرية المستقرة. 